\title{
A Comparison of Mental Health Problems among Children with Alopecia Areata or Atopic Dermatitis and Their Parents
}

\author{
Charilaos Karambetsos ${ }^{1}$, Constantinos Kouskoukis ${ }^{1}$, \\ George Giannakopoulos ${ }^{2^{\star}}$, Eirini Agapidaki ${ }^{2}$, Constantinos Mihas ${ }^{2}$, \\ Alexandra Katsarou ${ }^{3}$, Constantinos Miridakis ${ }^{4}$, Argiro Vatakis ${ }^{2}$ \\ and Gerasimos Kolaitis ${ }^{2}$ \\ ${ }^{1}$ Department of Dermatology, Democritus University of Thrace, Alexandroupolis, Greece. \\ ${ }^{2}$ Department of Child Psychiatry, Athens University Medical School, "Aghia Sophia" \\ Children's Hospital, Athens, Greece. \\ ${ }^{3}$ Department of Dermatology, Athens University Medical School, "Andreas Syggros" \\ Hospital, Athens, Greece. \\ ${ }^{4}$ Department of Dermatology, "Penteli" Children's Hospital, Athens, Greece.
}

Authors' contributions

This work was carried out in collaboration between all authors. All authors read and approved the final manuscript.

Research Article

Received $29^{\text {th }}$ May 2012 Accepted $21^{\text {st }}$ November 2012 Published 21 ${ }^{\text {st }}$ December 2012

\section{ABSTRACT}

Aims: There is an increased interest in the psychosocial impact of pediatric skin diseases on children and their families. The present study tried to examine possible differences regarding mental health problems among children with alopecia areata (AA) or atopic dermatitis (AD), and their parents.

Study Design: Cross-sectional study.

Place and Duration of Study: Department of Dermatology, "Penteli" Children's Hospital and Department of Dermatology, Athens University Medical School, "Andreas Syggros" Hospital, Athens, Greece, between February 2004 and February 2009.

Methodology: Parents of 51 pediatric outpatients (54.9\% boys) with a diagnosis of either AD or AA (mean age $=8.0 \pm 1.8$ years) and a control group of 12 children and their parents completed the Symptom Checklist-90-R (SCL-90-R) and the Child Behavior 
Checklist (CBCL). Differences among AA, AD, and the control group were examined.

Results: Both $A A$ and $A D$ groups had significantly $(P<.001)$ higher mean values across several $\mathrm{CBCL}$ scales compared to healthy controls. However, the controls seemed to exhibit less mental health symptoms than the normative Greek samples, a finding reducing the value of the control group. Children's Anxious/Depressed, Withdrawn, Somatic complaints and Social problems had significantly higher mean values in the AA group compared to the AD group. Parental mental health symptoms did not differ significantly between the two disease groups, but they were significantly higher in patient groups compared to control group.

Conclusion: Children's and parents' mental health symptoms may be important targets of thorough assessment and treatment among pediatric $A D$ and $A A$ populations.

Keywords: Alopecia areata; atopic dermatitis; children; parents; mental health.

\section{INTRODUCTION}

The psychosocial impact of skin diseases is well documented, although it is often underrecognized [1]. Elevated mental health symptoms have been reported in pediatric outpatients with chronic dermatologic diseases, including atopic dermatitis (AD), alopecia areata, vitiligo or psoriasis [2-8].

In preschoolers with severe AD, Daud et al. [5] found that their mothers reported significantly more child's clinginess/ dependency (i.e. being upset if left and taking some time to get over it), mild fearfulness (especially of strangers, doctors and of bath or water) and sleep problems (i.e. waking at night three times a week or more) compared with matched controls. In a study by Absolon et al. [2], school-aged children with moderately severe or severe AD presented with twice the rate of psychological disturbance compared with a control group, according to maternal reports. Self-reported depressive and anxiety symptoms have been found in children and adolescents with psoriasis or vitiligo, with mixed results regarding the effect of age and clinical severity on the psychosocial impact of the skin disease $[3,4,9]$. E.g. one study [9] found that vitiligo related to the severity of depression in children, but no association was observed in adolescents. Another study [4] concluded that quality of life of adolescents with vitiligo was closely related to depressive and anxiety symptoms, rather than the clinical severity of the condition itself.

The findings regarding the impact of pediatric AA seem of particular interest, since there has been a discrepancy between self-reports and psychiatric interviews or parents' reports. In a US sample of 12 children with AA, although structured interviews revealed a higher rate of anxiety or depressive disorders, self-reports did not suggest that significant psychopathology was present [7]. Similarly, a Greek study Liakopoulou et al. [6] showed that all children with AA exhibited symptomatology of anxiety or depression or both according to psychiatric interviews and they had more anxious/ depressed, withdrawn, aggressive/ delinquent, social and attention problems according to their parents' reports. However, children themselves reported only more anxiety (difficulties in concentration and physiological symptoms of anxiety) and not depressive symptoms compared to controls. These discrepancies could be partially attributed to restrictions of understanding or expressing subjective emotional states in children with AA, although the disagreement between informants is common in child and adolescent mental health. 
Psychological difficulties caused by a pediatric skin disease, mainly by $A D$, have been studied not only for the child but also for their parents. Warschburger et al. [10] found that parents (mainly mothers), whose children had AD (especially chronic eczema), had higher than normal level of psychological distress that was directly related to parentally observed eczema severity. On the contrary, Absolon et al. [2] did not manage to find any differences in levels of mental distress between mothers of children with $A D$ and parents of a control group. The role of parental mental health symptomatology needs further investigation, since it may affect the clinical management and possibly the course of a pediatric dermatologic disease, especially through increasing life stress, beyond the burden on the individual and interpersonal level [11].

To our knowledge, little evidence exists regarding the comparison of psychological consequences caused by skin diseases. The only somewhat relevant findings suggest that health related quality of life among children with $A D$ is more impaired than those with the majority of other common skin disorders except for scabies [12] and psoriasis [13]. No previous study has compared the psychological disturbance presented in AD vs. AA. The present study tried to expand previous literature through examining possible differences regarding children's and parents' mental health symptomatology between different types of skin disease, i.e. $A D$ and $A A$. We hypothesized that differences in age of onset (i.e. $A D$ usually appears in infancy before age 2 years, while the usually sudden loss of hair in $A A$ appears in school age or later) and in physical symptoms/ treatment (itchy patches usually on the hands and feet and sleep disturbance, and serious restrictions in everyday life in $A D$ vs. visible stigmatizing bald patches on the scalp in AA) may influence the psychosocial impact on affected children and their parents.

\section{METHODOLOGY}

\subsection{Participants}

The study was conducted at the Department of Dermatology, "Penteli" Children's Hospital and Department of Dermatology, Athens University Medical School, "Andreas Syggros" Hospital in Athens, Greece. Eligible for inclusion were all children and their parents, diagnosed with AA with disease duration $>6$ months or AD with SCORAD > 20 [14], who were followed as outpatients in the abovementioned health service. The period of recruitment was between February 2004 and February 2009. Inclusion criteria were child's age between 6-14 years and the parents' ability to read Greek and complete the questionnaires themselves. Exclusion criteria were diagnosis of developmental pervasive disorder or mental retardation, and a comorbid chronic illness. No patient was on psychiatric medication. Each month during the recruitment period, the first scheduled outpatient with AA or $A D$ fulfilling inclusion criteria was recruited alternately in the two abovementioned hospital departments. A total of 60 subjects were recruited and 51 families agreed to participate in the study ( $85 \%$ response rate). A control group of healthy children visiting outpatient clinic for minor pediatric conditions was also recruited after randomization stratifying for age and gender. Of the 15 controls recruited, 12 families agreed to participate (67\% response rate). The subjects refusing to participate did not differ significantly from the participants regarding to child's gender and age in AA, AD and control group. Each family was free to decide which parent would fill in the questionnaires concerning their children. Forty parent-reported child measures completed by mothers were returned. Re-contacting respondents in order to collect any missing values was employed. The institutional review board gave ethical approval to the study. Written parental informed consent and child assent were obtained. 


\subsection{Materials and Procedures}

Diagnosis of $A A$ or $A D$ was based on clinical grounds and age of onset, disease duration and severity, pruritus, family history of similar disease or autoimmune diseases and associated systemic complaints were noted in detail. Sociodemographic information and past medical and psychiatric history were recorded for children and parents.

The Child Behavior Checklist (CBCL) [15] is a 113-item parent-report checklist measuring a child's emotional/behavioral problems. Parents rate the frequency of specific behaviors in their children during the previous 6 months. All items are rated on a 3-point rating scale $(0=$ not true, $1=$ somewhat true, and $2=$ very true). The Greek version of the instrument can be scored in three different ways: a) eight empirically based syndromes scales (Anxious/Depressed, Withdrawn, Somatic complaints, Social problems, Thought problems, Attention problems, Delinquent behavior, Aggressive behavior, b) two second order scales (Internalizing including Anxious/Depressed, Withdrawn, and Somatic complaints scales, and Externalizing including Delinquent behavior and Aggressive behavior scales), and c) a Total problems score. The CBCL is a widely used empirically validated and reliable measure and Greek nation-wide normative data have been published [16].

In order to assess parent mental health symptoms the Greek version of the Symptom Checklist-90-Revised (SCL-90-R) was administered [17]. A standardization study has supported the validity of the instrument and its usefulness in psychiatric research and clinical practice in the Greek population [18]. The SCL-90-R is a 90-item multidimensional questionnaire designed to screen for a broad range of psychological problems. Each of the 90 items is rated on a five-point Likert scale of distress, ranging from $0=$ not at all to $4=$ extremely in terms of "how much discomfort that problem has caused you during the past week including today." The Global Severity Index (GSI), the mean rating across all items, was used for assessing parent mental health symptoms. The psychometric properties of the SCL-90-R GSI have been found acceptable in previous research [19] and support its use as a self-report measure.

\subsection{Statistical Analysis}

All continuous variables are described as mean and standard deviation, while categorical variables are described as absolute $(\mathrm{N})$ and relative (\%) frequencies. Potential univariate associations of the categorical variables with the disease type were evaluated using Pearson's $x^{2}$ or Fisher's exact tests. Differences in the continuous variables between the two diseases $(A A$ and $A D)$ and controls were tested using Student's t-test, after testing for the equality of variances using Levene's test.

In order to assess the effect of skin disease on children's and parents' mental health symptoms, 10 multiple linear regression models were constructed, always adjusting for child's gender and age. The 10 dependent variables were the aforementioned eight empirically based syndromes scales (Anxious/Depressed, Withdrawn, Somatic complaints, Social problems, Thought problems, Attention problems, Delinquent behavior, Aggressive behavior) and both paternal and maternal GSI. The regression models always included three explanatory variables (type of skin disease, child's gender and age). Due to the inflation of type I error because of multiple testing, $p$-value was considered significant if $P<.003$ (Bonferroni adjustment, 20 comparisons). Data were analyzed using STATA ${ }^{\text {TM }}$ statistical software (Version 9.0, Stata Corporation, College Station, TX 77845, USA). 


\section{RESULTS AND DISCUSSION}

The sample consisted of 63 children (51 patients and 12 controls; $52.4 \%$ boys). Thirty seven children $(72.5 \%$ of patients) suffered from AA. No missing value was present throughout the whole sample. Mean age was $8.1 \pm 1.9$ years. No significant association between gender and type of disease was found (boys with AA: $48.6 \%$ vs. girls with AA: $51.4 \%$, boys with AD: $71.4 \%$ vs. girls with $\mathrm{AA}: 28.6 \%, P=.145)$. Mean age did not differ between children with different type of disease (AA: $8.1 \pm 1.9$, AD: $7.6 \pm 1.6, P=.322)$. Mean age and gender distribution did not differ between patients and controls $(8.0 \pm 1.8 \mathrm{vs}$. $8.6 \pm 2.1, P=.315$, boy patients: $54.9 \%$, boy controls: $41.7 \%, P=.525$ ).

As seen in Table 1, where the explanatory variables are compared by type of disease, Anxious/Depressed, Withdrawn, Somatic complaints, and Social problems had significantly $(P<.001)$ higher mean values in the AA group. When comparing study groups with controls, it was found that all measures of children emotional and behavioral problems except for Delinquent behavior differed significantly between children with AA and controls. Withdrawn, Somatic complaints, Social problems, and Delinquent behavior did not differ significantly between $A D$ and control group.

Table 1. Comparisons of child emotional and behavioral problems (as measured through the Child Behavior Checklist) among AA, AD and control group

\begin{tabular}{|c|c|c|c|c|c|c|}
\hline Variable & $\begin{array}{l}\text { AA group } \\
(\mathrm{N}=37)\end{array}$ & $\begin{array}{l}\text { AD group } \\
(N=14)\end{array}$ & $\begin{array}{l}\text { Control group } \\
(\mathrm{N}=12)\end{array}$ & $\begin{array}{l}P \\
\text { value }^{1}\end{array}$ & $\begin{array}{l}P \\
\text { value }^{2}\end{array}$ & $\begin{array}{l}P \\
\text { value }^{3}\end{array}$ \\
\hline & (Mean \pm SD) & (Mean \pm SD) & (Mean \pm SD) & & & \\
\hline Anxious/Depressed & $10.4 \pm 5.1$ & $4.0 \pm 3.3$ & $0.7 \pm 0.8$ & $<.001$ & $<.001$ & .002 \\
\hline Withdrawn & $4.0 \pm 2.3$ & $1.3 \pm 1.1$ & $0.5 \pm 0.8$ & $<.001$ & $<.001$ & .047 \\
\hline Somatic complaints & $6.0 \pm 4.7$ & $2.4 \pm .6$ & $1.7 \pm 1.8$ & $<.001$ & $<.001$ & .222 \\
\hline Social problems & $4.6 \pm 3.0$ & $2.0 \pm 1.7$ & $1.7 \pm 1.3$ & $<.001$ & $<.001$ & .586 \\
\hline Thought problems & $4.9 \pm 2.6$ & $4.0 \pm 2.7$ & $0.8 \pm 0.8$ & .278 & $<.001$ & .001 \\
\hline Attention problems & $3.6 \pm 2.0$ & $4.8 \pm 1.9$ & $1.8 \pm 1.1$ & .058 & $<.001$ & $<.001$ \\
\hline $\begin{array}{l}\text { Delinquent } \\
\text { behavior }\end{array}$ & $2.7 \pm 2.6$ & $3.5 \pm 2.8$ & $1.2 \pm 0.8$ & .347 & .003 & .010 \\
\hline $\begin{array}{l}\text { Aggressive } \\
\text { behavior }\end{array}$ & $8.3 \pm 6.5$ & $9.9 \pm 1.9$ & $4.0 \pm 1.2$ & .195 & $<.001$ & $<.001$ \\
\hline
\end{tabular}

No significant association was found between parental educational status and skin disease type. Maternal educational status had a significantly different distribution between controls and AA $(P<.001)$ as well as AD group $(P=.001)$. In particular, low maternal educational status was found in $67.6 \%$ of the AA group, $57.1 \%$ of the AD group and $0 \%$ of the control group.

GSI as a measure of parental mental health symptoms was not found significantly different between the two skin disease groups. On the contrary, both paternal and maternal GSI was significantly higher in both aforementioned groups when compared with controls (Table 2). 
Table 2. Comparisons of parental mental health symptoms (as measured through the Symptom Checklist-90-R) among $A A, A D$ and control groups

\begin{tabular}{lllllll}
\hline Variable & $\begin{array}{l}\text { AA group } \\
(N=37)\end{array}$ & $\begin{array}{l}\text { AD group } \\
(N=14)\end{array}$ & $\begin{array}{l}\text { Control group } \\
(N=12)\end{array}$ & $\begin{array}{l}\boldsymbol{P} \\
\text { value }^{1}\end{array}$ & $\begin{array}{l}\boldsymbol{P} \\
\text { value }^{2}\end{array}$ & $\begin{array}{l}\boldsymbol{P} \\
\text { value }^{3}\end{array}$ \\
\hline (Mean \pm SD) & (Mean \pm SD) & (Mean \pm SD) & & & \\
\hline Paternal GSI & $0.8 \pm 0.3$ & $0.8 \pm 0.4$ & $0.3 \pm 0.2$ & .992 & $<.001$ & $<.001$ \\
Maternal GSI & $0.9 \pm 0.3$ & $0.8 \pm 0.3$ & $0.3 \pm 0.1$ & .458 & $<.001$ & $<.001$ \\
\hline$S D=$ Standard Deviation; $G S I=$ Global Severity Index; ${ }^{1} P$ values of the comparisons made between \\
$A A-A D$ groups; ${ }^{2} P$ values of the comparisons made between $A A-$ Control groups; ${ }^{3} P$ values of the \\
comparisons made between $A D-$ Control groups.
\end{tabular}

The results from multiple linear regression analysis evaluating the skin disease groups are shown in Table 3. AD (compared to $A A$ ) had a significant inverse effect on Anxious/Depressed and Withdrawn scales, after adjustment for child's age and gender.

This study was an effort to examine possible differences regarding children's and parents' mental health symptomatology between different types of skin disease, i.e. AD and AA. Results indicate that children with $A A$ or $A D$ and their parents show more mental health symptoms compared to healthy controls. Moreover, parent-reported child internalizing problems are related more strongly with $A A$ than $A D$, whereas parents' mental health symptoms are not significantly associated with the type of skin disease.

Previous literature has documented the psychosocial impact of pediatric $A D$ and $A A$ on children and their parents according to parents' reports $[2,5,6,10]$. However, no previous study has examined the psychological disturbance presented in AD vs. AA, although some studies have compared impairments in health-related quality of life among children with various dermatologic diseases except for AA $[12,13]$. Compared to the normative Greek sample published by Roussos et al. [16], the AA patients in the present sample presented with more internalizing and externalizing problems, while the AD patients show more somatic complaints and similar problems to the normative Greek sample regarding social problems and internalizing problems, such as anxious/depressed and withdrawn. Moreover, the controls seemed to exhibit less mental health symptoms than the normative Greek sample, a finding that reduces the value of the control group. In addition, in the control group the maternal educational status was significantly higher than in the patient groups. This difference may have influenced the observed differences, since a higher parental educational level may be associated with better mental health outcomes for both parents and their children. 
Table 3. Multiple linear regression analysis for the effect of skin disease type on all measured children's emotional and behavioral difficulties variables and parental global severity index adjusting for child's gender and age (presentation omitted)

\begin{tabular}{|c|c|c|c|c|c|c|}
\hline Dependent variable & Explanatory variable & $\begin{array}{l}\text { Unstandardized } \\
\text { beta coefficient }\end{array}$ & {$[95 \% \mathrm{Cl}]$} & & $P$ & $R^{2}(\%)$ \\
\hline Anxious/Depressed & $\begin{array}{l}\text { AD vs. AA } \\
\text { Girls vs. boys } \\
\text { Child's age (per } 1 \text { year increase) } \\
\text { Constant }\end{array}$ & $\begin{array}{l}-6.53 \\
-0.23 \\
-0.09 \\
11.27\end{array}$ & $\begin{array}{l}-9.64 \\
-3.01 \\
-0.86 \\
4.80\end{array}$ & $\begin{array}{l}-3.43 \\
2.56 \\
0.68 \\
17.74\end{array}$ & $\begin{array}{l}<.001 \\
.870 \\
.818 \\
.001\end{array}$ & $28.2 \%$ \\
\hline Withdrawn & $\begin{array}{l}\text { AD vs. AA } \\
\text { Girls vs. boys } \\
\text { Child's age (per } 1 \text { year increase) } \\
\text { Constant }\end{array}$ & $\begin{array}{l}-2.86 \\
-0.81 \\
0.03 \\
4.18\end{array}$ & $\begin{array}{l}-4.17 \\
-1.98 \\
-0.30 \\
1.45\end{array}$ & $\begin{array}{l}-1.54 \\
0.37 \\
0.35 \\
6.91\end{array}$ & $\begin{array}{l}<.001 \\
.175 \\
.876 \\
.003\end{array}$ & $29.7 \%$ \\
\hline Somatic complaints & $\begin{array}{l}\text { AD vs. AA } \\
\text { Girls vs. boys } \\
\text { Child's age (per } 1 \text { year increase) } \\
\text { Constant }\end{array}$ & $\begin{array}{l}-4.05 \\
-1.87 \\
0.04 \\
6.66\end{array}$ & $\begin{array}{l}-6.65 \\
-4.21 \\
-0.61 \\
1.23\end{array}$ & $\begin{array}{l}-1.44 \\
0.47 \\
0.68 \\
12.09\end{array}$ & $\begin{array}{l}.003 \\
.114 \\
.910 \\
.017\end{array}$ & $18.9 \%$ \\
\hline Social problems & $\begin{array}{l}\text { AD vs. AA } \\
\text { Girls vs. boys } \\
\text { Child's age (per } 1 \text { year increase) } \\
\text { Constant }\end{array}$ & $\begin{array}{l}-2.53 \\
0.19 \\
-0.01 \\
4.56\end{array}$ & $\begin{array}{l}-4.33 \\
-1.43 \\
-0.46 \\
0.81\end{array}$ & $\begin{array}{l}-0.73 \\
1.81 \\
0.44 \\
8.32\end{array}$ & $\begin{array}{l}.007 \\
.816 \\
.959 \\
.018\end{array}$ & $15.7 \%$ \\
\hline Thought problems & $\begin{array}{l}\text { AD vs. AA } \\
\text { Girls vs. boys } \\
\text { Child's age (per } 1 \text { year increase) } \\
\text { Constant }\end{array}$ & $\begin{array}{l}-1.17 \\
-0.82 \\
-0.11 \\
6.24\end{array}$ & $\begin{array}{l}-2.91 \\
-2.38 \\
-0.54 \\
2.61\end{array}$ & $\begin{array}{l}0.57 \\
0.74 \\
0.32 \\
9.86\end{array}$ & $\begin{array}{l}.184 \\
.298 \\
.611 \\
.001\end{array}$ & $5.5 \%$ \\
\hline Attention problems & $\begin{array}{l}\text { AD vs. AA } \\
\text { Girls vs. boys } \\
\text { Child's age (per } 1 \text { year increase) } \\
\text { Constant }\end{array}$ & $\begin{array}{l}1.24 \\
-0.39 \\
0.25 \\
1.80\end{array}$ & $\begin{array}{l}-0.02 \\
-1.52 \\
-0.07 \\
-0.83\end{array}$ & $\begin{array}{l}2.50 \\
0.74 \\
0.56 \\
4.42\end{array}$ & $\begin{array}{l}.053 \\
.492 \\
.121 \\
.175\end{array}$ & $12.3 \%$ \\
\hline Delinquent behavior & $\begin{array}{l}\text { AD vs. AA } \\
\text { Girls vs. boys } \\
\text { Child's age (per } 1 \text { year increase) } \\
\text { Constant }\end{array}$ & $\begin{array}{l}0.94 \\
0.63 \\
0.01 \\
2.32\end{array}$ & $\begin{array}{l}-0.82 \\
-0.95 \\
-0.43 \\
-1.36\end{array}$ & $\begin{array}{l}2.71 \\
2.21 \\
0.45 \\
5.99\end{array}$ & $\begin{array}{l}.286 \\
.428 \\
.971 \\
.211\end{array}$ & $3.2 \%$ \\
\hline
\end{tabular}


British Journal of Medicine \& Medical Research, 3(1): 162-172, 2013

Contd. Table 3

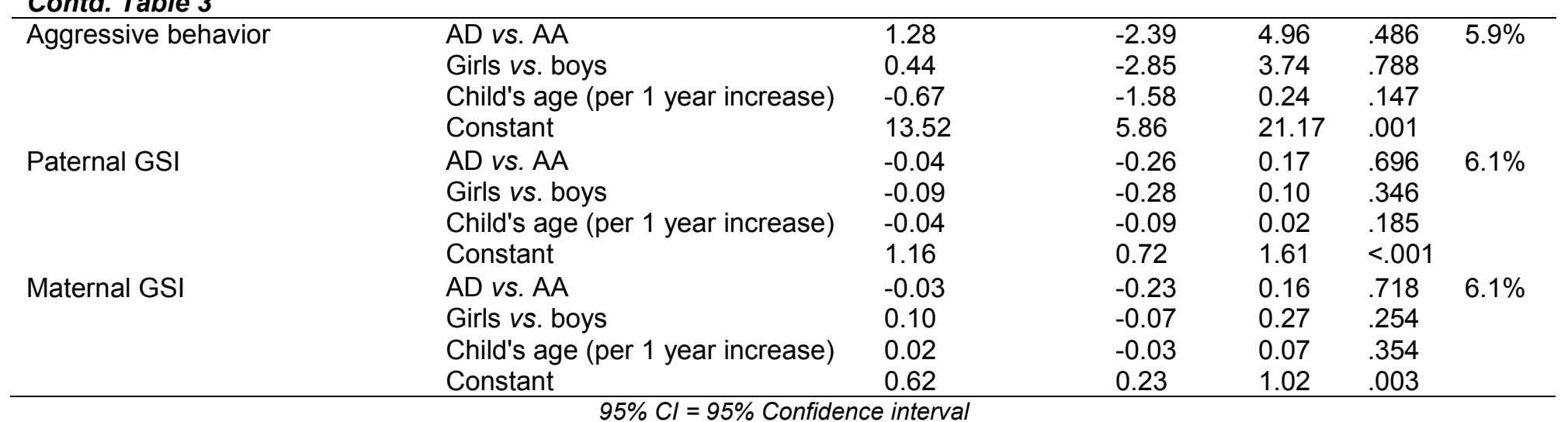


The present study did not manage to detect any differences in parents' mental health symptoms between AA and AD groups, although, in consistency with a previous study [10], it found that parents with children suffering from $A A$ or $A D$ reported more mental health symptoms compared to parents with healthy children. Moreover, our findings suggest that children with AA present more internalizing problems in general and anxiety/depression, withdrawal, somatic complaints and social problems in particular than those with AD. The hair loss and the visibility of the bald patches on the scalp may significantly affect the child's self-image and self-esteem. The adverse effects on such inner dimensions and the possible stigmatization in social contexts and in peer relations may explain to some extent the internalizing nature of the mental health problems presented in the AA group. Moreover, the age of disease onset may also influence the observed differences, with children suffering from $A D$ possibly being more adjusted to their disease, since $A D$ appears more commonly during infancy. The present results suggest that a greater emphasis should be placed on addressing and treating possible mental health problems among school-aged children with $A A$ and $A D$. Special attention should be paid to internalizing problems that are underrecognized by parents and professionals. Clinicians should always include a thorough and sensitive diagnostic interview with the children themselves beyond other informants.

The present findings should be interpreted in the context of some limitations. First, to diminish the burden of the examination on the patients we did not use adequate diagnostic interviews to screen for co-morbid psychiatric disorders. Second, the study was based only on parent-reports that limit the interpretation of the results. In addition, the sample size was rather small, leading to a low statistical power and a selection bias may limit the generalizability of results. In particular, the significant higher maternal educational status (compared to the patient groups) and the fewer children's mental health symptoms (compared to normative data) in the control group raises concerns. Last, the cross-sectional design of the study did not allow us to examine variations over time or make causal inferences.

\section{CONCLUSION}

Regardless of its limitations, the present study suggests that children's and parents' mental health symptoms may be important targets of thorough assessment and treatment among pediatric $A D$ and $A A$ populations.

\section{CONSENT}

All authors declare that 'written informed consent was obtained from the patient (or other approved parties) for publication of this case report and accompanying images.

\section{ETHICAL APPROVAL}

All authors hereby declare that all materials and procedures have been examined and approved by the appropriate ethics committee and have therefore been performed in accordance with the ethical standards laid down in the 1964 Declaration of Helsinki. 


\section{COMPETING INTERESTS}

Authors have declared that no competing interests exist.

\section{REFERENCES}

1. Hong J, Koo B, Koo J. The psychosocial and occupational impact of chronic skin disease. Dermatol Ther. 2008;21:54-9.

2. Absolon CM, Cottrell D, Eldridge SM, Glover MT. Psychological disturbance in atopic eczema: the extent of the problem in school-aged children. $\mathrm{Br} J$ Dermatol. $1997 ; 137: 241-5$.

3. Bilgic A, Bilgic O, Akis HK, Eskioglu F, Kilic EZ. Psychiatric symptoms and healthrelated quality of life in children and adolescents with proriasis. Pediatr Dermatol. 2010;27:614-7.

4. Choi S, Kim DY, Whang SH, Lee JH, Hann SK, Shin YJ. Quality of life and psychological adaptation of Korean adolescents with vitiligo. J Eur Acad Dermatol Venereol. 2010;24:524-9.

5. Daud LR, Garralda ME, David TJ. Psychosocial adjustment in preschool children with atopic eczema. Arch Dis Child. 1993;69:670-676.

6. Liakopoulou M, Alifieraki T, Katideniou A, Kakourou T, Tselalidou E, Tsiantis J, Stratigos J. Children with alopecia areata: psychiatric symptomatology and life events. J Am Acad Child Adolesc Psychiatry. 1997;36:687-684.

7. Reeve EA, Savage TA, Bernstein GA. Psychiatric diagnoses in children with alopecia areata. J Am Acad Child Adolesc Psychiatry. 1996;35:1518-22.

8. Titman PS, Barker $\mathrm{C}$, Smith $\mathrm{CH}$. The psychological impact of chronic eczema on children and their families. Br J Dermatol. 2001;145(S59):128-9.

9. Bilgic A, Bilgic O, Akis HK, Eskioglu F, Kilic EZ. Depression, anxiety and health-related quality of life in children and adolescents with vitiligo. Clin Exp Dermatol. 2011;36:360365.

10. Warschburger P, Buchholz HT, Petermann F. Psychological adjustment in parents of young children with atopic dermatits: which factors predict parental quality of life? $\mathrm{Br} \mathrm{J}$ Dermatol. 2004:150:304-11.

11. Diaz-Atienza F, Gurpegui M. Environmental stress but not subjective distress in children or adolescents with alopecia areata. J Psychosom Res. 2011;71:102-7.

12. Lewis-Jones MS, Finlay AY. The Children's Dermatology Life Quality Index (CDLQI $\left.{ }^{\odot}\right)$ : initial validation and practical use. $\mathrm{Br} J$ Dermatol. 1995;132:942-9.

13. Beattie PE, Lewis-Jones MS. Parental knowledge of topical therapies used in the treatment of atopic dermatitis. Clin Exp Dermatol. 2003;28:549-53.

14. Sprikkelman A, Tupker R, Burgerhof $H$, Schouten J, Brand $P$, Heymans $H$, van Aalderen W. Severity scoring of atopic dermatitis: a comparison of three scoring systems. Allergy. 1997;9:944-9.

15. Achenbach TM. Manual for the Child Behavior Checklist/4-18 and 1991 profile. Burlington, VT, USA: University of Vermont, Department of Psychiatry; 1991.

16. Roussos A, Karantanos G, Richardson C, Hartman C, Karajiannis D, Kyprianos S, Lazaratou H, Mahaira O, Tassi M, Zoubou V. achenbach's child behavior checklist and teachers' report form in a normative sample of Greek children 6-12 years old. Eur Child Adolesc Psychiatry. 1999;8:165-72.

17. Derogatis LR. The Symptom Checklist-90-revised. Minneapolis, MN: NCS Assessments; 1992. 
18. Donias S, Karastergiou A, Manos N. Standardization of the symptom checklist-90-R rating scale in a Greek population. Psychiatriki. 1991;2:42-8.

19. Schmitz N, Hartkamp N, Kiuse J, Franke GH, Reister G, Tress W. The Symptom Check-List-90-R (SCL-90-R): a German validation study. Qual Life Res. 2000;9:18593.

(c) 2013 Karambetsos et al.; This is an Open Access article distributed under the terms of the Creative Commons Attribution License (http://creativecommons.org/licenses/by/3.0), which permits unrestricted use, distribution, and reproduction in any medium, provided the original work is properly cited.

Peer-review history:

The peer review history for this paper can be accessed here: http://www.sciencedomain.org/review-history.php?iid=163\&id=12\&aid=812 